\title{
Manejo da podridão-de-Sclerotium em pimentão em um argisolo no Amazonas
}

\author{
Rosalee Albuquerque COELHO NETTO ${ }^{1}$, Andréia Aline Bastos FERREIRA ${ }^{1}$, Hiroshi NODA ${ }^{1}$
}

\begin{abstract}
RESUMO
A podridão-de-Sclerotium é uma doença comum em plantas da família Solanaceae na Amazônia. Visando avaliar estratégias de manejo para esta doença em pimentáo (Capsicum annuum, L. Solanaceae), foi conduzido experimento em campo em blocos casualizados com parcelas subdivididas e seis repetiçôes, em Argissolo Vermelho-Amarelo artificialmente infestado com Sclerotium rolfsii. O tratamento principal foi a cobertura do solo (cobertura do solo com serragem ou solo nu). Os tratamentos secundários consistiram na adição ao solo de: 1) composto vegetal (3 L por cova), 2) arroz colonizado com Trichoderma

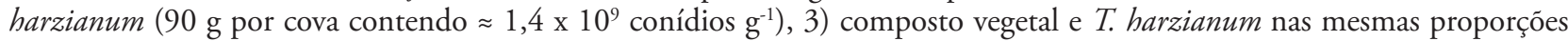
descritas anteriormente e 4) testemunha. Todas as plantas receberam apenas adubaçáo orgânica com composto vegetal na proporção de 1,5 L por cova, exceto as dos tratamentos com $3 \mathrm{~L}$ de composto por cova. A parcela principal foi constituída de três fileiras com dez plantas de pimentão $(0,50$ x 1,0 m) e cada subparcela continha três fileiras com cinco plantas. A incidência da podridáo-de-Sclerotium foi avaliada duas vezes por semana. A cobertura morta favoreceu significativamente a ocorrência da doença. Nas parcelas com esse tratamento o aumento da intensidade da doença, expressa em área abaixo da curva de progresso da doença (AACPD), foi 35,5\% maior, em comparaçáo com as parcelas sem cobertura morta. A aplicaçáo de T. harzianum ou o incremento na quantidade de composto (de 1,5 para $3 \mathrm{~L}$ por cova) reduziu a AACPD em $38,1 \%$ e $37,5 \%$, respectivamente. A aplicação de T. harzianum ou o incremento na quantidade de composto, mesmo nos tratamentos com cobertura morta, reduziu significativamente a AACPD em 52,8\% e em 55,1\%, respectivamente, em comparaçáo com o tratamento apenas com cobertura morta. Esses resultados sugerem que a utilizaçáo de T. harzianum e o aumento na quantidade de composto por cova são estratégias eficientes de manejo da podridão-de-Sclerotium em pimentáo. A cobertura morta com serragem não deve ser utilizada em áreas infestadas com S. rolfsii.
\end{abstract}

PALAVRAS-CHAVE: Capsicum annuum, Sclerotium rolfsii, Trichoderma harzianum, controle, biológico, cobertura morta.

\section{Southern blight management of bell pepper in an argissol in the Amazonas State}

\begin{abstract}
Southern blight is a common disease in plants belonging to the Solanaceae family in the Amazon. To compare southern blight management strategies for bell pepper (Capsicum annuum, L. Solanaceae) a field experiment was conducted in a split plot design with main plots arranged in randomized blocks, with six replicates for each treatment, in a red-yellow Argisol (Ultisol) artificially infested with Sclerotium rolfsii. The main factor was soil cover (sawdust mulch or bare soil) The secondary factors were the incorporation to the soil: 1) compost (3 L by planting hole), 2) rice colonized by Trichoderma harzianum (90 $\mathrm{g}$ by planting hole, with $\approx 1.4 \times 10^{9}$ conidia $^{-1}$ ) and 3) compost and T. harzianum in the same proportion described previously; 4) control. All plants were fertilized with $1.5 \mathrm{~L}$ of compost by planting hole except those in the treatments with $3 \mathrm{~L}$ of compost by hole. The main plot had three rows with ten bell pepper plants $(0.50 \times 1.0 \mathrm{~m})$ and the subplot, three rows with five plants. Southern blight incidence was accessed twice a week. The sawdust mulch increased the disease incidence significantly. In the mulched plots the disease intensity, expressed as the area under disease progress curve (AUDPC), increase $35.5 \%$ compared with bare soil. Trichoderma harzianum or the increase in the amount of compost ( $1.5 \mathrm{~L}$ to $3 \mathrm{~L}$ by planting hole) reduced the AUDPC by $38.1 \%$ and of $37.5 \%$, respectively. Furthermore T. harzianum or the increase in the amount of compost, even with sawdust mulch added, reduced the AUDPC by $52.8 \%$ and in $55.1 \%$, respectively, in comparison with mulch alone. These results suggested that the utilization of T. harzianum or the increase in the amount of compost by planting hole are viable strategies to southern blight management in bell pepper. The sawdust surface mulch is not recommended in an $S$. rolfsii infested area.
\end{abstract} KEYWORDS: Capsicum annuum, Sclerotium rolfsii, Trichoderma harzianum, biocontrol, mulch.

1 Instituto Nacional de Pesquisas da Amazônia, Coordenação de Sociedade, Ambiente e Saúde, Caixa Postal 2223, 69080-971, Manaus, AM; *:autor para correspondência, e-mail: rcoelho@inpa.gov.br 


\section{INTRODUÇÃO}

$\mathrm{Na}$ produção de hortaliças na Amazônia, que é essencialmente de pequena escala, a podridão-de-Sclerotium causada por Sclerotium rolfsii Sacc. [Athelia rolfsii (Curzi) Tu \& Kimbrough], é uma doença comum (Lourd 1993), principalmente em plantas da família Solanaceae. Sclerotium rolfsii é um parasita facultativo que causa podridão na base do caule em muitas espécies de plantas e que pode sobreviver no solo, na forma de escleródios, por períodos longos (Punja 1985). Estratégias eficientes e de baixo custo para o manejo da podridáo-de-Sclerotium seriam de grande utilidade para os agricultores locais. O controle químico de patógenos habitantes do solo, além de não ser uma prática recomendável para a agricultura praticada na regiấo, é difícil e pode causar desequilíbrio na microflora do ambiente (Gamliel et al. 2000). Por outro lado, devido principalmente aos perigos associados ao uso de agrotóxicos há um interesse crescente de produtores e consumidores por alimentos produzidos sem o uso desses produtos o que se reflete no rápido crescimento do mercado de produtos orgânicos em todo o mundo (Willer e Minou 2007) e no início desse tipo de produção de hortaliças no estado do Amazonas (Gallo 2011).

No manejo da podridão-de-Sclerotium a abordagem que tem apresentado os melhores resultados consiste em uma combinação de práticas culturais, com resistência genética e agentes de biocontrole (Sahni et al. 2008).

No controle biológico da podridão-de-Sclerotium, espécies do gênero Trichoderma se destacam pela grande capacidade de inibição do crescimento micelial e da produção de escleródios de S. rolfsii (Adandonon et al. 2006). Outra estratégia de manejo de patógenos habitantes do solo tem sido a adição de matéria orgânica que, além de melhorar a estrutura e a fertilidade do solo, contribui com o aumento da populaçáo de organismos benéficos e, auxilia no controle biológico podendo até mesmo, promover o desenvolvimento de solos supressivos (Bailey e Lazarovits 2003; Hadar e Gorodecki 1991; Blum e Rodríguez-Kábana 2004). Alguns suplementos orgânicos estimulam a germinação dos escleródios de $S$. rolfsii (Blum e Rodrigues-Kábana 2004) tornando-os mais sensíveis a ação de microrganismos antagonistas (Hadar e Gorodecki 1991).

A cobertura do solo, orgânica ou plástica, pode contribuir na diminuição da temperatura e na manutenção da umidade na camada superior do solo, estimulando o crescimento das plantas e ajudando no controle de ervas invasoras (Hutton e Handley 2007). Se a cobertura usada é orgânica, pode melhorar a fertilidade do solo e reduzir a população de fitopatógenos neste ambiente (Kumar et al. 2004; Shtienberg et al. 2010). Este trabalho objetivou avaliar o efeito da cobertura do solo com serragem, do incremento da quantidade de matéria orgânica e de um isolado local de Trichoderma harzianum Rifai, no manejo da podridão-de-Sclerotium em pimentão (Capsicum annuum L.) em um Argissolo no Amazonas.

\section{MATERIAL E MÉTODOS}

O experimento foi conduzido na Estação Experimental Alejo von der Pahlen do Instituto Nacional de Pesquisas da Amazônia (INPA), localizada no $\mathrm{km} 14$ da rodovia AM 10 (030.' S; 60 01' W de Greenwich) em Manaus, em 2009. O solo da área é do tipo Argissolo Vermelho-Amarelo álico, com textura arenosa e de baixa fertilidade (Tabela 1). O clima local é caracterizado como Afi segundo o sistema de Köppen-Geiger (Peel et al. 2007), com temperatura média de $26^{\circ} \mathrm{C}$ (máxima de 35 a $39^{\circ} \mathrm{C}$ e mínima de 19 a $21^{\circ} \mathrm{C}$ ) e precipitação anual de 1900 - $2300 \mathrm{~mm}$ (Embrapa 1982).

\section{Delineamento experimental e Condução do Experimento}

O delineamento experimental foi em blocos ao acaso em parcelas subdivididas com seis repetiçóes. Os tratamentos principais consistiram na cobertura ou náo do solo com serragem (camada de $3 \mathrm{~cm}$ de espessura) e os tratamentos secundários consistiram, na adiçáo ao solo de: 1) composto vegetal (3 L por cova), 2) arroz colonizado com Trichoderma harzianum Rifai, na proporção de $90 \mathrm{~g}$ por cova $\left(\approx 1,4 \times 10^{9}\right.$ conídios $\left.\mathrm{g}^{-1}\right)$,3) composto vegetal e arroz colonizado com T. harzianum nas proporçóes descritas anteriormente e 4) testemunha.

Todas as plantas, exceto as dos tratamentos com $3 \mathrm{~L}$ de composto por cova, foram adubadas, na ocasiáo do transplante, com 1,5 L de composto por cova. As características químicas do composto utilizado estão apresentadas na Tabela 1. Durante a condução do experimento, a serragem foi reposta uma vez, nas parcelas com este tratamento, de modo a manter o solo coberto. As plantas foram irrigadas por aspersão.

A parcela experimental consistiu em uma área de $15 \mathrm{~m}^{2}$ com três fileiras com dez plantas de pimentão e cada subparcela com uma área de $7,5 \mathrm{~m}^{2}$ com três fileiras com cinco plantas

Tabela 1- pH, carbono, matéria orgânica (M.O.) e cátions trocáveis do solo da área experimental em Manaus e do composto utilizado.

\begin{tabular}{|c|c|c|c|c|c|c|c|c|c|c|c|c|c|}
\hline \multirow{2}{*}{ Amostra } & \multirow{2}{*}{$\mathrm{pH}$} & C & M.0. & $\mathrm{N}$ & $\mathrm{P}$ & K & $\mathrm{Na}$ & $\mathrm{Ca}$ & $\mathrm{Mg}$ & $\mathrm{Al}$ & $\mathrm{Fe}$ & $\mathrm{Zn}$ & $\mathrm{Mn}$ \\
\hline & & \multicolumn{3}{|c|}{$\mathrm{g} \mathrm{kg}^{-1}$} & \multicolumn{3}{|c|}{$\mathrm{mg} \mathrm{dm}^{-3}$} & \multicolumn{3}{|c|}{$\mathrm{cmol}_{\mathrm{C}} \mathrm{dm}^{-3}$} & \multicolumn{3}{|c|}{$\mathrm{mg} \mathrm{dm}^{-3}$} \\
\hline Solo & 5,12 & 10,94 & 18,82 & - & 40,00 & 20,00 & 3,00 & 0,73 & 0,37 & 0,28 & 131,00 & 16,70 & 2,66 \\
\hline Composto & 6,95 & 141,00 & 243,00 & 7,06 & 604,74 & 454,00 & - & 17,59 & 9,05 & 0,05 & 62,00 & 19,00 & 44,00 \\
\hline
\end{tabular}

pH em água; Matéria Orgânica (M.0) = C (carbono orgânico) x 1,724, Walkley-Black; N - Kjeldahl; P, Na, K, Fe, Zn, Mn, Cu - Extrator Mehlich-1; Ca, Mg - Extrator KCl 1 mol L-1 
no espaçamento de $0,50 \times 1,0 \mathrm{~m}$. A cultivar de pimentáo utilizada foi Casca Dura Ikeda (ISLA Sementes Ltda., Porto Alegre, RS). As mudas transplantadas para o local definitivo aos quarenta e dois dias da semeadura, foram produzidas em tubetes de $132 \mathrm{~mm}$ de comprimento e $36,5 \mathrm{~mm}$ de diâmetro interno, contendo substrato comercial Plantmax HT (DDL Agro Indústria, São Paulo, SP).

\section{Infestação do solo e quantificação da população de Sclerotium rolfsii na área experimental}

A área experimental foi inicialmente arada, gradeada e plantada com feijão-caupi (Vigna unguiculata (L.) Walp.) cv. BR 3 Tacuateua no espaçamento de 0,4 x 0,6 m. Na fase de floração as plantas foram cortadas, picadas com facáo e deixadas sobre o solo. Nove dias depois foi feita a infestação do solo distribuindo-se $125 \mathrm{~g}$ de arroz colonizado com $S$. rolfsii por $\mathrm{m}^{2}$ de área. Dois meses depois foi aplicado calcáreo dolomítico na proporção de $2 \mathrm{t}$ ha ${ }^{-1}$ e após 30 dias, as mudas de pimentáo foram transplantadas.

O isolado de $S$. rolfsii utilizado foi obtido de plantas de pimentão apresentando sinais e sintomas de podridão-deSclerotium, coletadas no município de Iranduba, AM (isolado INPA 1700). Para produção do inóculo, grãos de arroz foram imersos em água por 12 horas, escorridos com peneira e autoclavados, por dois dias consecutivos, por 20 minutos, em sacos de polipropileno contendo na boca um anel de cano de PVC (40 mm de largura x 38,1 mm de diâmetro) preso com uma liga de borracha e um tampão de algodáo. Após o resfriamento do arroz, dois discos $(0,5 \mathrm{~cm}$ de diâmetro) de colônia de $S$. rolfsii cultivada por sete dias em meio batatadextrose-ágar (BDA), em placas de Petri, foram transferidos para cada saco. Os sacos foram mantidos em laboratório com temperatura aproximada de $25^{\circ} \mathrm{C} \mathrm{e}$, em dias alternados, durante 30 dias, o arroz no interior dos sacos foi agitado para uniformizar o crescimento do fungo. Para infestação do solo o inóculo dos diferentes sacos foi uniformizado e separado em porçóes que foram distribuídas na área.

Para quantificação da população de $S$. rolfsii na área experimental foi utilizada a metodologia descrita por Rodríguez-Kábana et al. (1980). Nove dias antes do transplante das mudas, amostras de solo foram coletadas na profundidade de $0 \mathrm{a} 10 \mathrm{~cm}$ com um trado de $1 \mathrm{~cm}$ de diâmetro na proporção de 10 amostras por bloco. As amostras de cada bloco foram misturadas, secas a sombra por dois dias e passadas por peneira de malha de $2 \mathrm{~mm}$. De cada amostra composta foram retiradas três porçóes de $25 \mathrm{~g}$ que foram distribuídas em três placas de Petri de $12 \mathrm{~cm}$ de diâmetro. Sobre o solo foram vertidos $10 \mathrm{~mL}$ de metanol a $1 \%$ e 48 horas depois foi feita a contagem das colônias de $S$. rolfsii e calculada a média de colônias por grama de solo.

\section{Preparo e quantificação do inóculo de Trichoderma harzianum}

O isolado INPA 1334 de T. harzianum utilizado no experimento foi identificado com base em características morfológicas e culturais de cultura monospórica (Samuels et al. 2012). O isolado foi obtido de madeira e selecionado entre vinte isolados de Trichoderma spp. obtidos de hospedeiras e substratos diversos, em um experimento preliminar, em casa-de-vegetação.

Para preparo do inóculo de $T$. harzianum, grãos de arroz foram autoclavados da mesma forma descrita anteriormente para multiplicação do $S$. rolfsii. O arroz foi infestado com dois discos $(0,5 \mathrm{~cm}$ de diâmetro) de colônia de $T$. harzianum cultivada, por nove dias, em BDA 1/5 (40 g de batata, $4 \mathrm{~g}$ de dextrose, $15 \mathrm{~g}$ de ágar). Diariamente, por 14 dias, o arroz no interior dos sacos foi agitado para uniformizar o crescimento do fungo. Os sacos foram mantidos em laboratório com temperatura aproximada de $25^{\circ} \mathrm{C}$. Após esse período o arroz foi transferido para bandejas plásticas e parcialmente seco em uma sala com ar condicionado $\left(22 \pm 1{ }^{\circ} \mathrm{C}\right)$, por cinco dias. Para quantificação da população do fungo no arroz expressa em unidades formadoras de colônias por grama $\left(\mathrm{ufc}^{-1}\right.$ ), o conteúdo das bandejas foi uniformizado e foram retiradas três amostras de $10 \mathrm{~g}$ de arroz colonizado que foram transferidas para Erlenmeyers $(125 \mathrm{~mL})$ contendo $90 \mathrm{~mL}$ de água destilada e esterilizada. As amostras foram agitadas por $5 \mathrm{~min}$ em agitador magnético e, foi feita a estimativa da população de conídios de T. harzianum no arroz por diluição em série em meio BDA acrescido de Rosa Bengala ( $\left.40 \mathrm{mg} \mathrm{L}^{-1}\right)$.

\section{Avaliação da doença e análise de dados}

A incidência da doença foi avaliada duas vezes por semana calculando-se o percentual de plantas mortas por parcela. Com os percentuais foram elaboradas curvas de progresso da doença e, posteriormente, calculadas as áreas abaixo das curvas de progresso da doença (AACPD) de acordo com Campbell e Madden (1990). Os dados foram submetidos à análise de variância e, quando significativos, submetidos ao teste de separação de médias de Scott-Knott a 5\% de probabilidade. As análises estatísticas foram efetuadas utilizando-se o programa SAEG, versão 9.0 (UFV).

Para determinar o efeito dos tratamentos na taxa de progresso da podridáo-de-Sclerotium as curvas de progresso de doença foram transformadas e analisadas para ajustamento aos modelos exponencial, Gompertz, linear, logístico e monomolecular usando o programa Epimodel (Nutter Jr. e Parker 1997).

\section{RESULTADOS}

Nove dias após o transplante já puderam ser observadas as primeiras plantas doentes e aos 23 dias a incidência média 
da podridão-de-Sclerotium nas parcelas apenas com cobertura morta foi de 73,83\% (Figura 1).

Nenhum dos tratamentos avaliados foi capaz de impedir o progresso da doença, no entanto, as aplicaçóes de T. harzianum $(P=0,0041), 3 \mathrm{~L}$ de composto por cova de plantio $(P=0,0046)$ e a cobertura morta $(P=0,0074)$ tiveram efeito significativo na redução da incidência da podridão-de-Sclerotium (Tabela 2). Os efeitos das interaçóes da cobertura morta com composto $(P=0,0046)$ e da cobertura morta com $T$. harzianum $(P=$ $0,0118)$ também foram significativos (Tabela 3 ).

Nas parcelas com cobertura morta o aumento da intensidade da doença, expressa como AACPD, foi de 35,5\% (Tabela 2). As aplicaçôes de $3 \mathrm{~L}$ de composto por cova $(P=$ $0,0046)$ e de $T$. harzianum $(P=0,0041)$, por outro lado, tiveram efeito significativo na redução da podridão-deSclerotium, expressa como AACPD, em 37,5\% e em 38,1\%, respectivamente (Tabela 2 ).

Com a aplicação T. harzianum, juntamente com a cobertura morta, observou-se uma reduçáo da incidência da

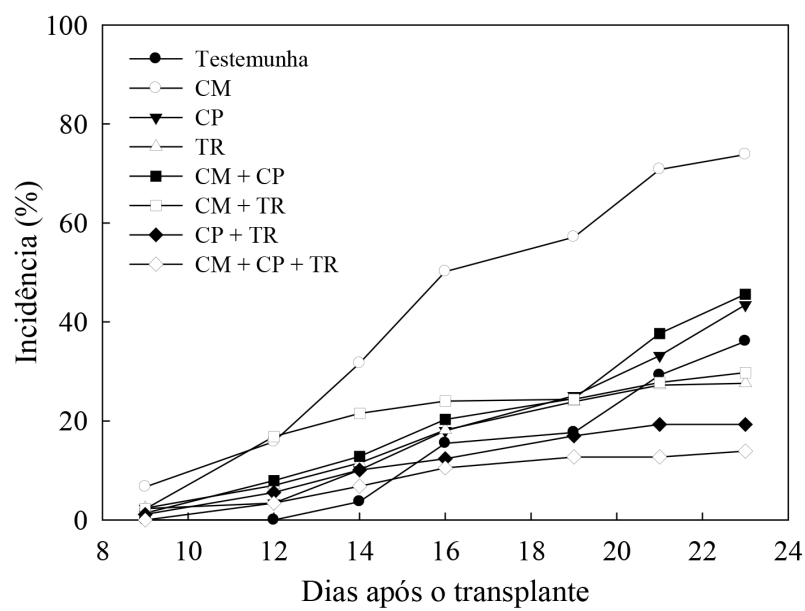

Figura 1 - Curvas de progresso da incidência da podridão-de-Sclerotium em plantas de pimentão submetidas aos tratamentos: $\mathrm{CM}=$ cobertura do solo com serragem, $\mathrm{CP}=$ composto orgânico ( $3 \mathrm{~L}$ por cova), $\mathrm{TR}=$ Trichoderma harzianum isolado INPA 1334 [90 $\mathrm{g}$ de arroz colonizado por cova $(\approx 1,4 \mathrm{x}$ $10^{9}$ conídios $\left.\mathrm{g}^{-1}\right)$ ] e testemunha. Todas as plantas, excluindo as do tratamento $\mathrm{CP}$ receberam $1,5 \mathrm{~L}$ de composto por cova.

Tabela 2 - Médias das áreas abaixo das curvas de progresso da incidência da podridão-de-Sclerotium em pimentão com e sem cobertura do solo com serragem (cobertura morta), com $3 \mathrm{~L}$ de composto por cova (com) ou com $1,5 \mathrm{~L}$ de composto por cova (sem) e com adição ou não, por cova, de $90 \mathrm{~g}$ de arroz colonizado por Trichoderma harzianum $\left(\approx 1,4 \times 10^{9}\right.$ conídios $\left.^{-1}\right)$.

\begin{tabular}{lcc}
\hline Tratamentos & com & sem \\
\hline Cobertura morta & $322,85 \mathrm{a}^{1}$ & $208,24 \mathrm{~b}$ \\
Composto & $204,25 \mathrm{~b}$ & $326,84 \mathrm{a}$ \\
Trichoderma harzianum & $203,12 \mathrm{~b}$ & $327,97 \mathrm{a}$ \\
\hline
\end{tabular}

${ }^{1} M e^{\prime}$ ias nas linhas seguidas por letras diferentes são significativamente diferentes entre si pelo teste $\mathrm{F}$ a $1 \%$ de significância.
podridão-de-Sclerotium, expressa como AACPD, de 52,8\% em comparaçáo com o tratamento apenas com cobertura morta (Tabela 3). Do mesmo modo, a aplicação de $3 \mathrm{~L}$ de composto por cova reduziu a intensidade da podridáo-de-Sclerotium, expressa como AACPD, em 55,1\%, em comparaçáo com o tratamento em que se utilizou 1,5 L de composto por cova e cobertura morta (Tabela 3).

Considerando a incidência da podridão-de-Sclerotium no final do período de avaliação, aos 23 dias após o transplante, observa-se que em todos os tratamentos com T. harzianum, independentemente da adiçáo de cobertura morta e do incremento na quantidade de composto, a incidência da doença foi significativamente menor, com valores entre $81,2 \%$ e $59,7 \%$ mais baixos, do que no tratamento apenas com cobertura morta (Tabela 4). A incidência da doença nos tratamentos com adiçáo de composto com ou sem cobertura morta ou no tratamento testemunha teve valores significativamente menores, entre $51,1 \%$ e $38,2 \%$ mais baixos, do que no tratamento apenas com cobertura morta (Tabela 4).

Tabela 3 - Valores médios das áreas abaixo das curvas de progresso da incidência da podridão-de-Sclerotium em pimentão com ou sem cobertura do solo com serragem (cobertura morta), com aplicação de 1,5 ou $3 \mathrm{~L}$ de composto por cova e com aplicação ou não de $90 \mathrm{~g}$ por cova de arroz colonizado com Trichoderma harzianum $\left(\approx 1,4 \times 10^{9}\right.$ conídios $\left.\mathrm{g}^{-1}\right)$.

\begin{tabular}{lccc}
\hline \multirow{2}{*}{ Tratamentos } & & \multicolumn{2}{c}{ Cobertura morta } \\
\cline { 3 - 4 } & & com & sem \\
\hline \multirow{2}{*}{ Composto } & $1,5 \mathrm{~L}$ & $445,61 \mathrm{aA}^{1}$ & $208,08 \mathrm{aB}$ \\
& $3,0 \mathrm{~L}$ & $200,10 \mathrm{bA}$ & $208,41 \mathrm{aA}$ \\
\hline \multirow{2}{*}{ T. harzianum } & com & $207,11 \mathrm{bA}$ & $199,13 \mathrm{aA}$ \\
& sem & $438,59 \mathrm{aA}$ & $217,35 \mathrm{aB}$ \\
\hline
\end{tabular}

${ }^{1}$ Médias nas colunas seguidas pelas mesmas letras minúsculas e nas linhas por maiúsculas não diferem significativamente diferentes entre si pelo teste de Skott-Knott a $5 \%$ de probabilidade.

Tabela 4 - Incidência média de podridão-de-Sclerotium (\%) aos 23 dias após 0 transplante e área abaixo da curva de progresso da doença relativa AACPDR (\%) em plantas de pimentão cultivadas em solo com ou sem cobertura com serragem e acrescido ou não de Trichoderma harzianum (isolado INPA 1334) e composto (3 L por cova).

\begin{tabular}{lcc}
\hline Tratamento $^{1}$ & $\begin{array}{c}\text { Incidência } \\
(\%)\end{array}$ & $\begin{array}{c}\text { AACPDR } \\
(\%)\end{array}$ \\
\hline Cobertura morta & $73,83 \mathrm{a}^{2}$ & 100,00 \\
Cobertura morta + Composto & $45,59 \mathrm{~b}$ & 61,75 \\
Composto & $43,44 \mathrm{~b}$ & 58,84 \\
Testemunha & $36,09 \mathrm{~b}$ & 48,88 \\
Cobertura morta + T. harzianum & $29,76 \mathrm{c}$ & 40,31 \\
T. harzianum & $27,58 \mathrm{c}$ & 37,36 \\
Composto + T. harzianum & $19,28 \mathrm{c}$ & 26,11 \\
Cobertura morta + Composto + T. harzianum & $13,91 \mathrm{c}$ & 18,84 \\
CV & 45,8 & \\
\hline
\end{tabular}

${ }^{1}$ As plantas de todos os tratamento, exceto os que receberam $3 \mathrm{~L}$ de composto por cova, foram adubados com $1,5 \mathrm{~L}$ de composto por cova.

${ }^{2} \mathrm{Os}$ valores na coluna seguidos pela mesma letra não diferem significativamente entre si pelo teste Scott-Knott a $5 \%$ de probabilidade.

${ }^{3} \mathrm{CV}=$ Coeficiente de variação 
Tabela 5 - Equações de regressão das curvas de progresso da podridão-deSclerotium com dados de incidência transformados para In(1/1-y) (modelo monomolecular) em plantas de pimentão submetidas a diferentes tratamentos.

\begin{tabular}{lcc}
\hline Tratamento* & $\begin{array}{c}\text { Equação de } \\
\text { regressão }\end{array}$ & $\mathrm{R}^{2^{* *}}$ \\
\hline Testemunha & $\mathrm{Y}=0,033 \mathrm{x}-0,363$ & 0,90 \\
Cobertura morta & $\mathrm{Y}=0,098 \mathrm{x}-0,914$ & 0,97 \\
Composto & $\mathrm{Y}=0,039 \mathrm{x}-0,402$ & 0,93 \\
Trichoderma harzianum & $\mathrm{Y}=0,024 \mathrm{x}-0,195$ & 0,98 \\
Cobertura morta + Composto & $\mathrm{Y}=0,041 \mathrm{x}-0,411$ & 0,94 \\
Cobertura morta + T. harzianum & $\mathrm{Y}=0,020 \mathrm{x}-0,091$ & 0,85 \\
Composto + T. harzianum & $\mathrm{Y}=0,016 \mathrm{x}-0,121$ & 0,98 \\
Cobertura morta + Composto + T. harzianum & $\mathrm{Y}=0,011 \mathrm{x}-0,084$ & 0,94 \\
\hline
\end{tabular}

* composto aplicado na proporcão de $3 \mathrm{~L}$ por cova; Trichoderma harzianum, isolado INPA 1334, aplicado na proporçẩo de $90 \mathrm{~g}$ de arroz colonizado por cova $\left(\approx 1,4 \times 10^{\circ}\right.$ conídios $\mathrm{g}^{-1}$ ); Todas as plantas, excluindo as do tratamento "Composto" receberam $1,5 \mathrm{~L}$ de composto por cova.

$\star \star \mathrm{R}^{2}=$ Coeficiente de determinação

As equaçóes de regressão das curvas de progresso da doença geradas pelo programa Epimodel (Nutter Jr. e Parker 1997) com os dados de incidência transformados em $\ln [1 /(1-y)]$, estáo apresentadas na Tabela 5.

$\mathrm{Na}$ área experimental, infestada artificialmente com $S$. rolfsii, a densidade de inóculo foi de 42,2 escleródios por 100 $\mathrm{g}$ de solo e não se observaram diferenças significativas, dessa variável, entre os blocos.

Não foi observada incidência de outras doenças nas plantas de pimentão durante a condução do experimento. A incidência de plantas cortadas por paquinhas (Neocurtilla hexadactyla Perty), no entanto, foi elevada, principalmente nos primeiros dias após o transplante. Cerca de $12 \%$ das plantas do experimento foram cortadas pela praga porém não foi observada diferença significativa entre os tratamentos com relação ao ataque da paquinha.

\section{DISCUSSÃO}

Há diversos relatos sobre os efeitos benéficos da cobertura morta na produção de pimentão (Diaz-Pérez 2010; Wang et al. 2010). Estes efeitos têm sido relacionados à melhoria da fertilidade (Wang et al. 2010) e a diminuição da temperatura do solo. Díaz-Perez (2010) observou que a produçáo, o número e o peso de frutos de pimentáo, diminuíram com a temperatura da rizosfera acima de $27^{\circ} \mathrm{C}$ e os tratamentos que favoreceram o aumento da temperatura na rizosfera acarretaram diminuição da produção de frutos. Em Manaus foram observados incrementos de $74 \%$ no peso de frutos e de $40 \%$ no número de frutos de pimentâo com a utilização de cobertura do solo com pó-de-serra, em comparação com a produçáo obtida em solo nu (Silva Filho et al 1986/87). Apesar de plantas de pimentão poderem ser bastante favorecidas com a diminuição da temperatura do solo proporcionada pela utilização de cobertura morta, esse eventual efeito benéfico não pode ser observado nas plantas do experimento devido a alta incidência da doença nas parcelas com esse tratamento. O fato de $S$. rolfsii ser um parasita facultativo com grande capacidade saprofítica, as excelentes condiçóes ambientais encontradas na Amazônia para o seu desenvolvimento, que incluem umidade elevada e temperatura ótima entre 27-30 ${ }^{\circ} \mathrm{C}$ (Punja 1985), e o estimulo à germinação de escleródios proporcionado por exsudatos liberados por matéria orgânica não compostada (Linderman e Gilbert 1969), explicam o porque da incidência da podridão-de-Sclerotium ter sido tão favorecida nas parcelas com cobertura morta. Em outras condiçôes ambientais, o efeito da cobertura morta sobre este patógeno pode ser bastante diferente. Por exemplo, em um cultivo de tomate (Solanum lycopersicum L.) na Carolina do Norte, EUA, a cobertura do solo com palha de trigo (Triticum spp.) não afetou a germinação de escleródios de $S$. rolfsii e diminuiu a incidência da podridáo-de-Sclerotium, em comparação com parcelas com solo nu (Bulluck III e Ristaino 2002). Por outro lado, em cultivo de amendoim (Arachis hypogaea L), também na Carolina do Norte, EUA, a adição de cobertura morta proporcionou aumento da densidade de inóculo de $S$. rolfsi sem, no entanto, aumentar a incidência da podridão-de-Sclerotium (Ferguson e Shew 2001). Na Amazônia, o uso da cobertura morta em cultivo de pimentáo poderia ser recomendado pelo significativo efeito observado na produção de frutos (Silva Filho et al 1986/87), porém apenas em áreas não infestadas ou com baixa densidade de inóculo de $S$. rolfsii.

O incremento na adição de matéria orgânica compostada de 1,5 L por cova para $3 \mathrm{~L}$ por cova, por outro lado, diminuiu significativamente a incidência da doença. Em tomateiros, a adubação orgânica favoreceu o aumento da população de microrganismos como fungos do gênero Trichoderma e bactérias fluorescentes do gênero Pseudomonas e a incidência da podridão-de-Sclerotium foi significativamente reduzida (Bulluck III e Ristaino 2002). Do mesmo modo, em cultivos de feijão (Phaseolus vulgaris L.) e de grão-de-bico (Cicer arietinum $\mathrm{L}$.) a adição de matéria orgânica compostada reduziu a incidência da podridáo-de-Sclerotium (Gorodecki e Hadar 1990). O efeito foi atribuído, principalmente, à presença de micorganismos antagônicos ao patógeno, no composto. Quando o composto foi submetido à radiação gama, o efeito supressivo à podridão-de-Sclerotium foi perdido (Gorodecki e Hadar 1990). A qualidade do composto empregado também afeta seu efeito supressivo. O curtimento prolongado diminui o efeito supressivo à germinação de escleródios de $S$. rolfsii devido, provavelmente, a mudanças na população dos microrganismos presentes, que ocorrem com a maturação do composto (Danon et al. 2007). Efeito similar foi observado para podridão-de-Rhizoctonia (Rhizoctonia solani Kühn,), ou seja, quanto mais curtido o composto, menor o efeito supressivo para a doença enquanto que a adição de altos níveis 
de celulose estimulou o desenvolvimento tanto da populaçáo do patógeno quanto do seu antagonista e eliminou o efeito supressivo do composto (Chung et al. 1988). Compostos precisam ter qualidade e maturidade adequadas para serem usados com sucesso no manejo de doenças. Pela variedade de materiais empregados e condiçóes de preparo nem todos os compostos proveráo resultados similares no controle de organismos fitopatogênicos. O problema da variação da supressividade para diferentes compostos poderia ser resolvido pelo uso de inoculantes específicos após o pico de aquecimento e antes que a colonização natural atinja níveis significantes (Hoitink et al. 1996).

Os dados da epidemia tiveram melhor ajuste ao modelo monomolecular que é, normalmente, o mais adequado para doenças monocíclicas (Nutter Jr. 2007), como é o caso da podridão-de-Sclerotium. A maior inclinaçáo da curva no tratamento com cobertura morta indica uma maior taxa de progresso da doença (r) em decorrência do favorecimento do patógeno por este tratamento. Nos tratamentos onde se utilizou T. harzianum as taxas de progresso das epidemias foram menores, indicando o efeito do agente de biocontrole sobre a doença.

Em solo natural, o padráo de distribuiçáo e a densidade de escleródios de $S$. rolfsii são influenciados pelos cultivos prévios e pelas práticas culturais adotadas (Punja et al. 1985). A incidência da podridáo-de Sclerotium está diretamente relacionada com a densidade de inóculo (Tomasino e Conway 1987). A densidade de inóculo utilizada no experimento, 42,2 escleródios por $100 \mathrm{~g}$ de solo, foi similar a encontrada em solos naturalmente infestados com $S$. rolfsii utilizados para cultivo comercial de amendoim nos EUA. Naquela área foi observada densidade média de 17,9 escleródios por $100 \mathrm{~g}$ de solo, com variaçáo de 0,67 a 75 escleródios por $100 \mathrm{~g}$ de solo na área mais densamente infestada (Punja et al. 1985). A cobertura do solo com serragem estimulou o desenvolvimento de S. rolfsii. Crescimento micelial branco e vigoroso, típico de $S$. rolfsii, e também a formação de escleródios puderam ser observados sobre a serragem no campo. Esse favorecimento do fungo resultou em um aumento na incidência de doença nas parcelas com este tratamento.

Isolados de Trichoderma spp. são bem conhecidos como bons antagonistas de S. rolfsii (Elad et al. 1980) e a população de Trichoderma spp. é, geralmente, elevada em solos agrícolas. Esse fungo sobrevive no seu nicho, que são as raízes de plantas saudáveis, utilizando diferentes mecanismos como micoparasitismo, antibiose e competição por nutriente e espaço. Espécies de Trichoderma aumentam a tolerância das plantas ao estresse por estimular o desenvolvimento das raízes e da planta, induzem resistência, promovem inativação de enzimas de patógenos e a solubilização e o sequestro de nutrientes inorgânicos do solo (Harman 2000).
Apesar de o grande volume de pesquisas que atestam a eficiência dos agentes de biocontrole no manejo de diversos problemas fitossanitários, poucos são comercializados atualmente. $\mathrm{O}$ registro de agentes de biocontrole, que até recentemente no Brasil seguia as mesmas exigências impostas aos agrotóxicos, envolvia altos recursos financeiros e um longo período para obtenção da documentação necessária. O processo de registro foi simplificado, para o caso dos agentes de controle biológico aceitos na agricultura orgânica, com a publicaçáo do decreto 6.913/09 (Brasil 2009). Nesse caso, o registro do agente de biocontrole segue um trâmite próprio e prioritário, inclusive com os agentes produzidos exclusivamente para uso próprio ficando isentos de registro.

A utilizaçáo de T. harzianum e o incremento na quantidade de matéria orgânica compostada podem ser alternativas para os produtores de hortaliças do Amazonas no manejo da podridãode-Sclerotium. Testes para avaliar a eficiência do controle com quantidades menores de inóculo de T. harzianum são necessários pois a quantidade testada no experimento (90 $\mathrm{g}$ de arroz colonizado por cova) poderia representar um aumento significativo nos custos de produçáo, principalmente utilizando arroz como substrato. Outros substratos de baixo custo, disponíveis localmente, constituídos principalmente de matérias de descarte da agroindústria como cascas de frutas, sementes trituradas e outros, devem ser testados na produção do inóculo de T. harzianum. A persistência do efeito supressivo, a eficiência em outros tipos de solo e com outras hospedeiras também precisam ser testadas bem como condiçôes de produção em maior escala, características de embalagem, condiçóes de armazenamento e vida de prateleira no ambiente Amazônico. O isolado INPA 1334 de T. harzianum, utilizado no experimento, por ser de origem local, não modificado geneticamente, poderia ser autorizado para uso em cultivo orgânico o que facilitaria o seu registro (Brasil 2009).

Argissolos são comuns na Amazônia e ocupam cerca de $30 \%$ da superfície total da regiāo (Sánchez 1981). Como o tipo de solo pode ter influência na incidência da podridãode Sclerotium (Le et al. 2012) os tratamentos precisam ser avaliados em outros tipos de solos para que as recomendaçóes possam ser generalizadas.

\section{CONCLUSÕES}

A cobertura do solo com serragem náo deve ser recomendada em áreas infestadas com $S$. rolfsii pois pode favorecer o aumento da incidência da doença. $\mathrm{O}$ incremento na quantidade de composto e a adiçấo de inóculo de Trichoderma harzianum (isolado INPA 1334) ao solo têm efeito significativo na diminuição da incidência da podridãode-Sclerotium. Apesar da produção e do modo de utilização do controlador biológico ser bastante simples, as quantidades 
de inóculo de T. harzianum a serem recomendadas, as condiçôes de produçáo e armazenamento e os substratos locais que propiciem uma redução nos custos de produção do inóculo ainda precisam ser testados assim como o efeito dos tratamentos em outros tipos de solo.

\section{AGRADECIMENTOS}

Os autores agradecem à Financiadora de Estudos e Projetos (FINEP), convênio 01.06.0380.00, pelo suporte financeiro.

\section{BIBLIOGRAFIA CITADA}

Adandonon, A.; Aveling, T.A.S.; Labuschagne, N.; Tamo, M. 2006. Biocontrol agents in combination with Moringa oleifera extract for integrated control of Sclerotium-caused cowpea dampingoff and stem rot. European Journal of Plant Pathology, 115 (4): 409-418.

Bailey, K.L.; Lazarovits, G. 2003. Suppressing soil-borne diseases with residue management and organic amendments. Soil and Tillage Research 72: 169-180.

Blum, L.E.B.; Rodríguez-Kábana, R. 2004. Effect of soil organic amendments on sclerotial germination, mycelial growth, and Sclerotium rolfsii-induced diseases. Fitopatologia Brasileira 29:66-74

Brasil, 2009. Decreto No 6.913, de 23 de julho de 2009. Acresce dispositivos ao Decreto no 4.074, de 4 de janeiro de 2002, que regulamenta a Lei no 7.802, de 11 de julho de 1989, que dispóe sobre a pesquisa, a experimentação, a produção, a embalagem e rotulagem, o transporte, o armazenamento, a comercialização, a propaganda comercial, a utilizaçáo, a importaçáo, a exportação, o destino final dos resíduos e embalagens, o registro, a classificação, o controle, a inspeção e a fiscalização de agrotóxicos, seus componentes e afins. Publicado no DOU de 24.7.2009. Disponível em: http://www.planalto.gov.br/ccivil_03/_Ato20072010/2009/Decreto/D6913.htm; Acesso em 12.11.2011.

Bulluck III, L.R.; Ristaino, J.B. 2002. Effect of synthetic and organic soil fertility amendments on southern blight, soil microbial communities, and yield of processing tomatoes. Phytopathology 92: 181-189.

Campbell, C.L.; Madden, L.V. 1990. Introduction to plant disease epidemiology. New York, John Wiley \& Sons. 532 p.

Chung, Y.R; Hoitink, H.A.H.; Lipps, P.E. 1988. Interactions between organic-matter decomposition level and soilborne disease severity. Agriculture, Ecosystems \& Environment 24 (13): 183-193.

Danon, M.; Zmora-Nahum, S.; Chen, Y.; Hadar, Y. 2007. Prolonged compost curing reduces suppression of Sclerotium rolfsii. Soil Biology and Biochemistry 39 (8): 1936-1946.

Diaz-Pérez, J.C. 2010. Bell pepper (Capsicum annuum L.) grown on plastic film mulches: effects on crop micoenvironment, physiological attributes, and fruit yield. HortScience 45: 11961204.
Elad, Y.; Chet, I,; Katan, J. 1980. Trichoderma harzianum: A biocontrol agent effective against Sclerotium rolfsii and Rhizocionia solani. Phytopathology 70:119-121.

Embrapa, 1982. Boletim agrometeorológico. Manaus, Embrapa/ UEPAE. 22 pp.

Ferguson, L.M.; Shew, B.B. 2001. Wheat straw mulch and its impacts on three soilborne pathogens of peanut in microplots. Plant Disease 85 (6): 661-667.

Gallo, M. 2011. Criaçấo de organismo certificador assegura qualidade de produção orgânica no Amazonas. Disponível em: http://www.amazonasnoticias.com.br/manaus/53-governocomeca-levantamento-fundiario-em-iranduba.pdf. Acesso em: $11 / 12 / 2011$

Gamliel, A.; Austerweil, M.; Kritzman, G. 2000. Non-chemical approach to soilborne pest management - organic amendments. Crop Protection 19 (8-10): 847-853.

Gorodecki, B.; Hadar, Y. 1990. Suppression of Rhizoctonia solani and Sclerotium rolfsii diseases in container media containing composted separated cattle manure and composted grape marc. Crop Protection 9 (4): 271-274.

Hadar, Y.; Gorodecki, B. 1991. Suppression of germination of sclerotia of Sclerotium rolfsii in compost. Soil Biology and Biochemistry 23: 303-306.

Harman, G.E. 2000. Myths and dogmas of bio-control: Changes in perceptions derived from research on Trichoderma harzianum T22. Plant Disease 84:377-393.

Hoitink, A.J.H.; Stone, A.G.; Grebus, M.E. 1996. Suppression of plant disease by composts. p. 373-381. In: Bertoldi, M. (Ed.). The Science of Composting. Blackie Academic \& Professional, Glasgow, UK.

Hutton, M.G.; Handley, D.T. 2007. Effects of silver reflective mulch, white inter-row, and plant density on yields of pepper in Maine. HortTechnology 17 (2): 214-219.

Kumar, V.; Mills, D.J.; Anderson, J.D.; Mattoo, A.K. 2004. Delayed senescence and disease tolerance of tomato plants cultivated in cover crop mulch correlates with accumulation of specific gene products. Acta Horticilturae 638:497-502.

Le, C. N.; Mendes, R.; Kruijt, M.; Raaijmakers, J. M. 2012. Genetic and phenotypic diversity of Sclerotium rolfsii in groundnut fields in central Vietnam. Plant Disease 96:389-397.

Linderman, R.G.; Gilbert, R.G. 1969. Stimulation of Sclerotium rolfsii in soil by volatile component of alfalfa hay. Phytopathology 59: 1366-1372.

Lourd, M. 1993. Os principais patógenos das plantas cultivadas na Ilha do Careiro. Amazoniana 12 (3/4): 565-576.

Nutter, Jr., F.W.; Parker, S.K. 1997. Fitting disease progress curves using EPIMODEL. p. 24-28. In: Franci, L.J.; Neher, D.A. (Eds.). Exercises in Plant Disease Epidemiology. APS Press, St. Paul, Minn.

Nutter, Jr., F.W. 2007. The role of plant disease epidemiology in developing successful integrated disease management programs. P. 45-79. In: Ciancio, A; Mukerji, K.G. General Concepts in Integrated Pest and Disease Management. Springer. The Neherlands. 
Peel, M.C.; Finlayson, B.L.; McMahon, T.A. 2007. Updated world map of the Köppen-Geiger climate classification. Hydrology and Earth System Sciences Discussion 4: 439-473.

Punja, Z.K.; Smith, V.L.; Campbell, C.L.; Jenkins, S.F. 1985. Sampling and extraction to estimate numbers, spatial pattern, and temporal distribution of sclerotia of Sclerotium rolfsii in soil. Plant Disease 69: 469-474.

Punja, Z.K. 1985. The Biology, ecology, and control of Sclerotium rolfsii. Annual Review of Phytopathology 23: 97-127.

Rodriguez-Kábana, R.; Beute. M.K.; Backman, P.A. 1980. A method for estimating numbers of viable sclerotia of Sclerotium rolfsii in soil. Phytopathology 70: 917-919.

Sahni, S.; Sarma, B.K.; Singh, D.P.; Singh, H.B.; Singh, K.P. 2008. Vermicompost enhances performance of plant growthpromoting rhizobacteria in Cicer arietinum rhizosphere against Sclerotium rolfsii. Crop Protection 27 (3-5): 369-376.

Samuels, G.J.; Chaverri, P.; Farr, D.F.; McCray, E.B. Trichoderma Online, Systematic Mycology and Microbiology Laboratory, ARS, USDA. Disponível em: http://nt.ars-grin.gov/taxadescriptions/ keys/TrichodermaIndex.cfm. Acesso em: 29/08/2012.

Sánchez, P.A. 1981. Suelos del Trópico: características y manejo. San José: IICA. 660pp.
Silva Filho, D.F.; Noda, H.; Ranzani, G. 1986/87. Efeito da cobertura morta sobre a produçáo de pimentáo (Capsicum annuum). Acta Amazonica 16/17: 19-26.

Shtienberg, D.; Elad, Y.; Bornstein, M.; Ziv, G.; Grava, A.; Cohen, S. 2010. Polyethylene mulch modifies greenhouse microclimate and reduces infection of Phytophthora infestans in tomato and Pseudocercospora cubensis in cucumber. Phytopathology 100: 97-104.

Tomasino, S.F.; Conway, K.E. 1987. Spacial pattern, inoculum density-disease incidence relationship, and populacion dynamics of Sclerotium rolfsii on apple rootstock. Plant Disease 71: 719724.

Wang, Q.; Klassen, W.; Evans, E.A.; Li, Y.; Codallo, M. 2010. Combination of organic and plastic mulches to improve the yield and quality of winter fresh market bell peppers (Capsicum annuum L.). HortScience 45: 701-706.

Willer, H.; Minou, Y. (Eds.). 2007. The World of Organic Agriculture. Statistics and Emerging Trends 2007. 9th edition. IFOAM \& FiBL Bonn, Germany.44 p. Disponível em: http:// www.orgprints.org/10506.

Recebido em: 07/04/2012

Aceito em: 10/10/2012 